\title{
Stochastic model of deteriorating cargo transshipment at port's terminal under irregular arrival of ships
}

\author{
Ludmiła Filina-Dawidowicz ${ }^{1, *}$, and Mykhaylo Postan ${ }^{2}$ \\ ${ }^{1}$ West Pomeranian University of Technology, Szczecin, Faculty of Marine Technology and Transport, \\ al. Piastów 17, 70310 Szczecin, Poland \\ ${ }^{2}$ Odessa National Maritime University, Department of Management, Marketing, and Logistics, \\ Mechnikov Str. 34, 65029 Odessa, Ukraine
}

\begin{abstract}
In the article the stochastic model is analyzed for deteriorating cargo transshipment taking into account the irregularity of arrived ships movement and cargo removing from warehouse with the regular surface transport. It is assumed that unloading rate of ships is given and fixed, but hold capacities of ships are randomly varying. During storage the cargo is subjected to deterioration with the given intensity. The problem of stationary probabilistic joint distribution of number of ships in terminal and quantity of cargo in warehouse is investigated. For this purpose the theory of Markov drift processes and methods of queueing theory are used. The problem of optimal value of deterioration rate is formulated and solved.
\end{abstract}

\section{Introduction}

The port terminals for transshipping and warehousing the perishable cargoes are the important links of transport-logistical chains in which transport streams of different kinds of transport are interacting. The effectiveness of such interaction is influenced by the regularity of transport units movement, the terms and cost of cargo delivery, as well as its safety. For perishable cargo transportation and warehousing, it is important to provide the optimal conditions for its storage between loading/unloading of transport units (TU). Therefore, these circumstances must be taken into consideration while port terminals design and operation.

Usually, for formal description of terminal functioning the combination of methods of the queueing theory (QT) and the storage (inventory) theory is used. For example, the significance of QT for project calculations lies in the fact that it makes it possible to predict variation of length of queues in a designed terminal and time of being in a queue of TU, that waits for beginning of loading or unloading for a remote prospect. Objectively existing variation and irregularity of movement of TU create difficult conditions for exploitation of production capacities of ports, that bring to necessity of reserves creation. The inventory theory makes it possible to give correct assessment of a level of expected amount of cargo

\footnotetext{
* Corresponding author: ludmila.filina@zut.edu.pl
} 
in a warehouse of a terminal and to determine its necessary capacity, to give scientific grounds for a value of operation load on structural elements of moorage constructions and to improve its reliability. Description of a terminal in a form of one or another queueing system is also necessary for giving the scientifically grounded assessment of expected values of economic results and expenses that relate to exploitation of a terminal in the long term.

At the same time, while examining a problem of formal description of a port terminal in terms of the mentioned above theories, many unsolved tasks remain related to finding of the key dependence of the main characteristics of technological elements on characteristics of incoming streams of TU. Characteristics of technological elements that were calculated not in the proper way can bring to additional demurrage of TU and ships, as well as to losses connected with such a demurrage. The mentioned problem is important for a theory and practice of port terminals design and operation, but the theoretical difficulties can occur during it solving which require non-trivial special researches.

\section{Literature review and problem statement}

During the last decade, the international trade growth of perishable goods is observed that influences the increase of production/transportation of products, such as food, medicines etc. Transportation and warehousing of such goods using different transport modes (water, railroad) require maintaining special regimes (e.g. temperature conditions) in ports terminals and warehouses, etc. [1-3]. In other words perishable products logistics faces the deterioration problem. It can deal with products spoilage, physical depletion, gradual loss of qualitative properties of materials with the passage of time and above all storage conditions changing $[4,5]$. Therefore, the great attention in theory of logistics and its applications is paid to the problem of deteriorating products flow control. The known models of inventory control theory cannot be applied directly in the process of perishable products production and transportation. In many situations arising in logistics management the adaptation and generalization of classical inventory control models is needed for the case of deterioration of perishable raw materials and finished product under prolonged transporting/warehousing. Recently, the inventory control models were reviewed by Williams \& Tokar [6] and Bakker, Riezebos \& Teunter [7], discussing main inventory system characteristics, i.e. price discounts, backordering or lost sales, single or multiple items, average cost or discounted cash flow, payment delay etc. In the works authored by Banerjee \& Agrawal [8], Li, Zhang \& Han [9] the inventory models for deteriorating products were proposed. It is naturally to suppose that the volume of perishable products deterioration depends on technical characteristics of refrigerating equipment and corresponding costs needed to support the special warehousing regimes $[10,11]$. In the articles [12-14] the simple models for optimal lot sizing of perishable product based on generalization of the classical Wilson and Wagner-Whitin models were studied. However, in these works the possibility of warehousing regime control was not considered. Our paper aims to further develop the optimal inventory control models for perishable product, mainly, to develop the stochastic optimization model for the case of perishable product coming through the port's terminal considering deterioration process control at warehouse and taking into account additional investments directed for this rate decreasing. This idea was firstly mentioned in our previous works $[10,11,15,16]$.

It is known that nowadays while port terminals design the methods of simulation and operations research are widely used for giving the scientific grounds for capacity planning $[17,18]$ that make it possible to model a terminal work. In the literature dedicated to the modelling of port terminals operation, the ready models of queueing systems were used for the long time, which considered the specific character of port operation insufficiently 
[19-21]. However, classical models of queueing theory were worked out mainly for solving the tasks of telecommunication system design, and for the most transport systems they are of little use. So, for example, they absolutely do not consider the factor of coordination of oncoming traffics in a terminal. For description of such traffics only a model of the stationary Poisson stream is usually used. At the same time, considering the present regulation of a transport operation (for example, in linear shipping), the TU streams, that come to a terminal, are not the Poisson ones but have some certain level of regularity.

The first researches that were dedicated to modelling of interaction of transport streams in a port in assumption of non-limited capacity of fronts of loading and unloading, were made in 70-80s of the last century. During the following two decades the accent in the researches was put on building and analysis of stochastic models of port terminals' work taking into consideration the finite capacity of loading and unloading fronts. In monograph [17] a level of research of this problem up to 2006 was analyzed, where stochastic models of transportation and storage systems are given with capacity limitation, that is built with the help of combination of methods of the storage (inventory) theory and QT. However, in it only relatively simple models of interaction of transport streams were analytically investigated in general, where one stream is regular, i.e. characterized by the constant rate of cargoes delivery (pickup). At the same time real transport streams have higher or lower level of irregularity and that is why they make interest for research of this more theoretically difficult case.

Among the latest researches in the field of modelling of interaction of transport streams in transit points a work [22] can be singled out, in which a model based on generalization of a classical model of Wagner - Whitin in the inventory theory is suggested for optimization of a coordination between a streams of ships (with the given schedule) and railway wagons. However, presented approach is efficient only for a case of fully controlled transport streams, the irregularity of TU arrival is not considered.

In the book [17] the analytical methods (with a help of a special class of Markov processes - Markov drift processes) are presented including enough researches of models of interactions (via a warehouse mainly) of transport streams in terminals for a case, when one of the TU streams (loaded and empty) is regular, and the other one is described by a model of the Poisson stream. In a case of an interaction of two irregular transport streams because of significant analytical difficulties within the Markov models, it was possible to investigate only the simplest case of interaction of two single TU. For solving the occurring mathematical difficulties and for getting the desired join queue-length distribution of TU and amount of cargo in a warehouse, it is necessary to make one or another simplifying assumptions, for example, related to unlimited capacity of one of the fronts of TU loading/unloading, unlimited capacity of a warehouse, etc. Above results are related to the usual cargo transhipment only, that is, to non-perishable cargo. In the article [11] the stochastic model of port's terminal was examined for transhipping the deteriorating cargo but under condition that one of the streams of TU is described by the model of compound Poisson process and another one is strong regular. That is why it is interesting to analyze more general case when the stream of ships is irregular but not obligatory is Poisson, for example, is finite or is described by the model renewal process. The analysis of such modelling case for deteriorating cargo is the aim of our paper.

\section{Description of general modeling scheme of port's terminal}

Let us consider the port's terminal that consists of one moorage and warehouse. The perishable cargo of one kind is delivered to a terminal with a single ship and immediately comes to a warehouse with rate $W$. The time of round voyage of the ship is random variable with the distribution function (d.f.) $A(t)$. The carrying capacity of ship is also random 
variable with the d.f. $G(x)$ and time of ship's unloading has the d.f. $B(t)=G(W t)$. It is assumed that both random variables are mutually independent.

All cargo that was delivered to a warehouse is removed from warehouse with a help of surface transport (trucks, wagons) regularly with the constant rate $U<W$. The cargo in warehouse is subjected to deterioration with the rate $a \xi(t)$, where $\xi(t)$ is the amount of storing cargo at moment of time $t$ (see Fig. 1).

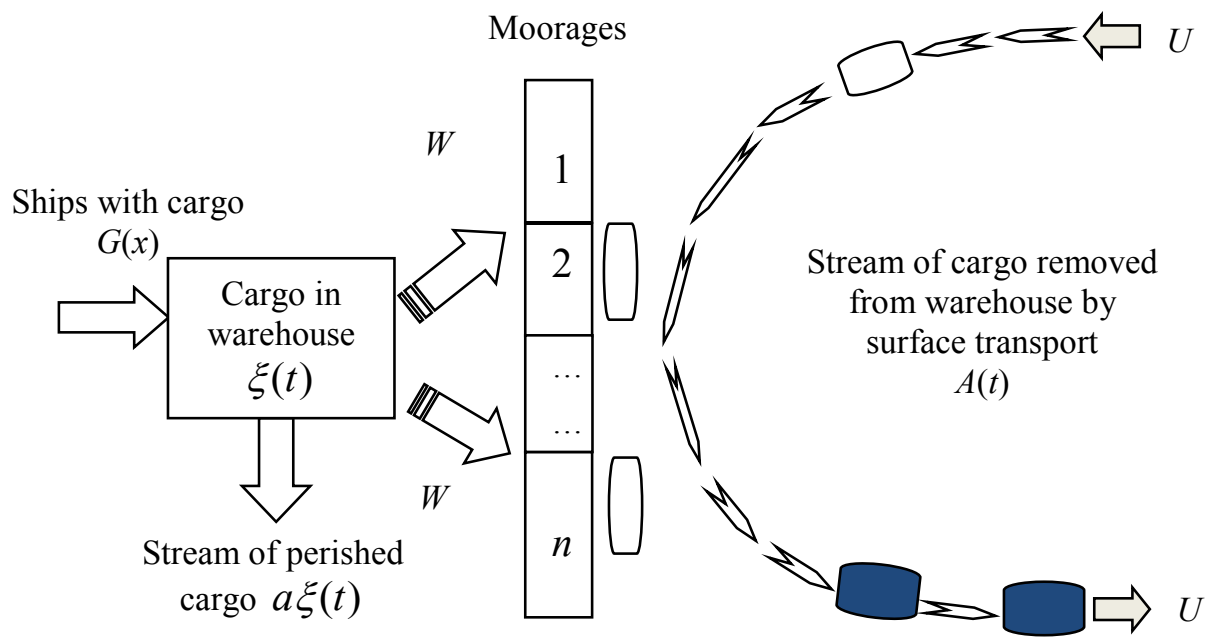

Fig. 1. Scheme of transport-warehousing system in port's terminal.

Remark. Our supposition that there are only single ship does not restrict the generality of terminal's model as a queueing system. If $A(t)$ is exponential distribution, then, as it is well known from the theory of queue $\mathrm{M} / \mathrm{G} / 1$ with infinite waiting room [23], the periods of time when a server is busy and is idle form an alternative renewal process. Therefore, if we will consider this more general case we can put $B(t)=\Pi(t)$, where $\Pi(t)$ is d.f. of busy period. From queueing theory [24], it follows that the Laplace-Stieltjes transform $\pi(z)$ of d.f. $\Pi(t)$ satisfies the functional equation

$$
\pi(s)=g\left(\frac{s+\lambda-\lambda \pi(s)}{W}\right), \operatorname{Re} s \geq 0,
$$

where

$$
g(z)=\int_{0}^{\infty} e^{-z x} d G(x), \operatorname{Re} z \geq 0 .
$$

Similarly it concerns the cases of one-server queueing systems of M/G/1 type with finite waiting room or with finite number of sources.

Let $v(t)$ be the number of ships that are in a terminal in the moment of time $t$, that is, $v(t)$ may take only two values: 0 or 1 . In mathematical respect our task is to find the limit (with $t \rightarrow \infty$ ) distribution of a random vector $(v(t), \xi(t))$. From the physical point of view it means that we examine the work of terminal in a steady-state regime (or in equilibrium). 


\section{Finding the limit probabilistic distribution of inventory level}

Due to above suppositions one can derive the following stochastic differential equation (with probability 1) describing the inventory level fluctuation in warehouse:

$$
\xi^{\prime}(t)=W(v(t)=1)-U \mathrm{I}(v(t)=0, \xi(t)>0)-a \xi(t),
$$

where $\mathrm{I}(A)$ is the indicator of an event $A$. From (1), it follows that $\xi(t)$ is the random walk defined on the semi-interval $[0, L)$, where $L=(W-U) / a$, i.e. 0 is sticky boundary and $L$ is attracting boundary for this walk.

Let us denote $\left\{t_{n}\right\}, n=1,2, \ldots$ the sequence of the moments of time when process $v(t)$ changes its states and denote

$$
F_{k}(x, t)=\mathbf{P}\{v(t)=k, \xi(t) \leq x\}, \Phi_{k n}(x)=\mathbf{P}\left\{v\left(t_{n}\right)=k, \xi\left(t_{n}\right) \leq x\right\}, 0 \leq x<L, k=0,1 .
$$

Our main goal is finding the limit distributions of process $(v(t), \xi(t))$ (assuming the existence of these limits).

$$
F_{k}(x)=\lim _{t \rightarrow \infty} F_{k}(x, t), \quad \Phi_{k}(x)=\lim _{n \rightarrow \infty} \Phi_{k n}(x), 0 \leq x<L, k=0,1 .
$$

For determination of the functions $\Phi_{k}(x), k=0,1$, from (1) and by theorem of total probability one can derive the following system of linear integral equations:

$$
\Psi_{0}(t)=\int_{+0}^{t} B(t-u) d \Psi_{1}(u)+\Psi_{1}(0) B(t), \Psi_{1}(t)=\int_{t}^{\infty}[1-A(h(u)-h(t))] d \Psi_{0}(u)+\Psi_{0}(t), t \geq 0,
$$

where

$$
\Psi_{k}(t)=\Phi_{k}\left(L\left(1-e^{-a t}\right)\right), k=0,1 ; h(t)=(1 / a) \ln \left[1+\rho\left(1-e^{-a t}\right)\right], \rho=\frac{W}{U}-1
$$

The equations (2) are the sequence of theorem of total probability. Furthermore, the functions $F_{k}(x)$ can be expressed through the functions $\Phi_{k}(x), k=0,1$, by the relations

$$
\begin{gathered}
F_{0}\left(L\left(1-e^{-a t}\right)\right)=2 \alpha /(\alpha+\beta)\left\{\Psi_{0}(t)+\int_{t}^{\infty}[1-A(h(u)-h(t))] d \Psi_{0}(u)\right\}, \quad \text { (3) } \\
F_{1}\left(L\left(1-e^{-a t}\right)\right)=2 /(\alpha+\beta)\left\{\Psi_{1}(0) \int_{0}^{t}(1-B(u)) d u+\int_{0}^{t t} \int_{0}^{t-u}(1-B(y)) d y d \Psi_{1}(u)\right\}, t \geq 0,
\end{gathered}
$$

where

$$
\alpha=\int_{0}^{\infty} t d A(t)<\infty, \quad \beta=\int_{0}^{\infty} t d B(t)<\infty
$$


Particularly, if

$$
A(t)=1-e^{-\lambda t}, t \geq 0
$$

then from (2) we obtain the following loaded Volterra integral equation of the $2^{\text {nd }}$ kind for determination of $\Psi_{1}(t)$ :

$$
\left[W+L a\left(1-e^{-a t}\right)\right] \Psi_{1}^{\prime}(t)=\lambda W e^{-a t} \int_{0}^{t}[1-B(t-x)] \Psi_{1}^{\prime}(x) d x+\lambda W \Psi_{1}(0) e^{-a t}[1-B(t)], t \geq 0,
$$

For applications it is sufficient to know the mean and the variation of inventory level. For calculation of

$$
\mathbf{E} \xi^{j}=\lim _{t \rightarrow \infty} \mathbf{E} \xi^{j}(t), j=1,2
$$

immediately from (3), (4) the following formulae are valid (we omit the routing calculations)

$$
\begin{gathered}
\mathbf{E} \xi=L\left\{1-\frac{2 a}{1+\lambda \beta} \Psi_{1}^{*}(a)\left[1+\lambda \frac{1-\beta(a)}{a}\right]\right\}, \\
\mathbf{E} \xi^{2}=L^{2}\left\{1-\frac{4 a \Psi_{1}^{*}(a)}{1+\lambda \beta}\left[1+\lambda \frac{1-\beta(a)}{a}\right]+\frac{4 a \Psi_{1}^{*}(2 a)}{1+\lambda \beta}\left[1+\lambda \frac{1-\beta(2 a)}{2 a}\right]\right\},
\end{gathered}
$$

where

$$
\Psi_{1}^{*}(s)=\int_{0}^{\infty} e^{-s t} \Psi_{1}(t) d t, \beta(s)=\int_{0}^{\infty} e^{-s t} d B(t), \operatorname{Re} s \geq 0 ; \beta=g / W, g=\int_{0}^{\infty} x d G(x)<\infty \text {. }
$$

Particularly, if

$$
G(x)=1-e^{-x / g}, x \geq 0
$$

(the Markov model), then formula (5) can be reduced to the following one

$$
\mathbf{E} \xi=L\left\{1-\frac{2 a \Psi_{1}^{*}(a)}{1+\lambda \beta}\left[1+\frac{\lambda \beta}{1+a \beta}\right]\right\}
$$

where, as it follows from equation (4),

$$
s \Psi_{1}^{*}(s)=\Psi_{1}(0)\left\{1+\lambda \rho \int_{0}^{\infty} e^{-(s+a+1 / \beta) t}\left[1+\rho\left(1-e^{-a t}\right)\right]^{(\lambda / a-1)} d t\right\}
$$

The constant $\Psi_{1}(0)$ may be found from condition

$$
\lim _{s \rightarrow+0} s \Psi_{1}^{*}(s)=1 / 2
$$


From this and (7) we find

$$
\Psi_{1}(0)=\frac{1}{2}\left\{1+\lambda \rho \int_{0}^{\infty} e^{-(a+1 / \beta) t}\left[1+\rho\left(1-e^{-a t}\right)\right]^{(\lambda / a-1)} d t\right\}^{-1}
$$

In practice, parameter $a$ is usually small. From the expression (7), (8) it may be shown that the following asymptotic formulae are valid:

$$
\begin{aligned}
& a \Psi_{1}^{*}(a) \approx \Psi_{1}(0)\left\{1+\frac{\lambda \rho[2 a+1 / \beta-\rho(\lambda+a)]}{(2 a+1 / \beta-\lambda \rho)^{2}}\right\}, \\
& \Psi_{1}(0) \approx \frac{1}{2}\left\{1+\frac{\lambda \rho[1 / \beta-\rho(\lambda+a)]}{(1 / \beta-\lambda \rho)^{2}}\right\}^{-1}, a \rightarrow 0 .
\end{aligned}
$$

The relations (9) are valid, for example, under condition

$$
\lambda \beta \rho<1
$$

or

$$
\lambda g<W U /(W-U)
$$

Note that in equilibrium from equation (1) we obtain

$$
\xi(t)=\int_{-\infty}^{t}[W \mathrm{I}(v(\tau)=1)-U \mathrm{I}(v(\tau)=0, \xi(\tau)>0)-a \xi(\tau)] d \tau,-\infty<t<\infty .
$$

(we moved up the initial moment to - $\infty$ and dropped out initial value $\xi(0)$ ). Applying the operator of mathematical expectation to both parts of (10) we obtain

$$
\mathbf{E} \xi(t)=\int_{-\infty}^{t}\left[W F_{1}(\infty, \tau)-U\left(1-F_{0}(0, \tau)\right)-a \mathbf{E} \xi(\tau)\right] d \tau,-\infty<t<\infty .
$$

After differentiation of both parts of equation (11) and accounting that $\mathbf{E} \xi(t)$ does not depend of time for stationary process we have

$$
a \mathbf{E} \xi=W F_{1}(\infty)-U\left(1-F_{0}(0)\right)
$$

Since

$$
F_{1}(\infty)=\lambda \beta /(1+\lambda \beta)
$$

from (12) we obtain finally

$$
\lambda g /(1+\lambda \beta)=U\left(1-F_{0}(0)\right)+a \mathbf{E} \xi .
$$


Relation (13) expresses so-called conservation law for transport-warehousing system under consideration. The expression in the right-hand side of equation (13) is the mean rate of cargo stream coming from ship to warehouse and in left-hand side is total intensity of cargo stream removed from the warehouse. The expression $a \mathbf{E} \xi$ is the average rate of deteriorated cargo stream removed from the warehouse.

From (13), one can find the stationary probability that there are no cargo in warehouse in arbitrary moment of time

$$
F_{0}(0)=1-\left(\frac{\lambda g}{1+\lambda \beta}-a \mathbf{E} \xi\right) / U
$$

where $\mathbf{E} \xi$ is defined by (4)- (8).

\section{Formulation of optimal inventory control problem}

The results obtained above allow us to formulate and solve the problem of optimal inventory control for managers of port's terminal. In the models of optimal inventory control of perishable product it is expediently to consider the parameter $a$ as control variable which is controlled by special investments directed into more modern refrigerating equipment $[10,15]$. It is naturally to consider parameter $a$ as a decreasing function of mentioned investments. Such function, for example, may have the following view

$$
a(v)=a_{0} /(1+k v)^{r}
$$

or

$$
a(v)=a_{0} \exp \left(-k v^{r}\right)
$$

where $a_{0}$ is the value of parameter $a$ when the above investments equals to 0 , i.e. it corresponds to norms of natural perish under old technology of storage; $k$ is a coefficient which characterizes the rate of cargo deterioration decreasing under positive value of investments directed into progressive storage technology; $r$ is a positive parameter, $r \leq 1$; $v$ is value of investments that port's terminal managers direct in the beginning of planning horizon from own profit for decreasing of cargo deterioration.

Let us evaluate the average cost per time unit $\bar{C}$ related to functioning of port's warehouse in steady-state regime. If we take into account only the cost for storage, the loss from cargo perish, and investments for decreasing the deterioration of cargo, then the expression for $\bar{C}$ takes the form

$$
\bar{C}(v)=\left(c_{s t}+p a\right) \mathbf{E} \xi+v / T
$$

where $c_{s t}$ is holding cost for cargo unit and per time unit; $p$ is price of product in good state; $T$ is a planning horizon. In expression (16), it is assumed that parameter $a$ depends of control variable $v$ according to one of the dependencies (14), (15), and expression $\mathbf{E} \xi$ is defined by the formulae (6), (7).

Since under condition $v \rightarrow \infty$ the parameter $a(v) \rightarrow 0$ (see (15), (16)) and $\mathbf{E} \xi$ tends to a finite limit [17,23], then $a \mathbf{E} \xi \rightarrow 0$ with the growth of $v$. 
Taking into account the conservation law (13), (14) the objective function (17) will take the form

$$
\bar{C}(v)=\left(c_{s t}+p a\right)\left[\frac{\lambda g}{1+\lambda \beta}-U\left(1-F_{0}(0)\right)\right]+v / T .
$$

The problem of parameter $v$ optimal value finding that minimizes the function (18) is sufficiently complex computational procedure, since this control parameter $v$ enters the integrals (see (6) - (8)), i.e. the objective function is not expressed through the elementary functions. Therefore, for this optimization problem solving a special computational algorithm is needed. In such a situation it is expediently to use some approximations, for example, asymptotic expansion under $a \rightarrow 0$ (see (9)).

\section{Conclusion}

The paper presents the development of the inventory control model for perishable cargo for the case of its servicing in port's terminal considering deterioration process control. It forms the next step in the development of inventory control theory considering irregularity of transport units movement and dependence of deterioration rate of cargo during its storage on the additional investments intended for this rate decreasing.

Presented stochastic model of port's terminal may be generalized in several directions, that will direct our future work. Two of them are noted below:

1) Refuse from the supposition of exponential distribution of inter-arrival periods of ships at terminal. In order to take into account more regular arrival of TU, it is possible to use the Erlang distribution or another kind of phase-type distribution [23, 24, 26]. But in a result, we must solve a more general system of integro-differential equation in respect of limit distribution of inventory level fluctuation $\xi(t)$. Another generalization may be based on application semi-Markov process for modeling the ships arrival.

2) Assume that the cargo is removed from warehouse irregularly, as well. The similar models (for non-perishable cargo) were studied in [17].

\section{References}

1. L. Chen, T. Notteboom, Distribution and Value Added Logistics in The Cold Chain Product Market with Application to the Role of Seaports. 5th ALRT Conference, Vancouver, June, 14-15, (2012)

2. O. Laguerre, H.M. Hoang, D. Flick, Experimental Investigation and Modeling in the Food Cold Chain: Thermal And Quality Evolution. Trends Food Sc. \& Techn., 29(2), 87-97 (2013)

3. Y. Zhang, X.D. Chen, An Optimization Model for the Vehicle Routing Problem in Multiproduct Frozen Food Delivery. J. of App. Res. and Techn., 12(2), 239-250 (2014)

4. J. Evans, Effects of Food and Beverages Storage, Distribution, Display and Customer Handling on Shelf Life. In: Kilcast, D., Subramaniam, P. (eds). Food and Beverage Stability and Shelf Life, Woodhead Publishing Limited, 273-300 (2011)

5. A. Kundu, P. Chakrabarti, T. Chakrabarti, An EOQ Model For Time-Dependent Deteriorating Items With Alternating Demand Rates Allowing Shortages By Considering Time Value of Money. Yug. J. of Op. Res., 23(2), 263-278 (2013)

6. B. D. Williams, T. Tokar, A Review of Inventory Management Research in Major Logistics Journals: Themes And Future Directions. The In. J. of Log. Manag., 19(2), 212-232 (2008) 
7. M. Bakker, J. Riezebos, R.H. Teunter, Review of Inventory Systems with Deterioration Since 2001. Europ. J. of Oper. Res., 221(2), 275-284 (2012)

8. S. Banerjee, S. Agrawal, Inventory Model for Deteriorating Items with Freshness and Price Dependent Demand: Optimal Discounting and Ordering Policies. App. Math. Mod., 52, 53-64 (2017)

9. Y. Li, S. Zhang, J. Han, Dynamic Pricing and Periodic Ordering for a Stochastic Inventory System With Deteriorating Items. Automatica, 76, 200-213 (2017)

10. M.Ya. Postan, L. Filina-Dawidowicz, Optimal Inventory Control for Perishable Items Under Additional Cost for Deterioration Reduction. LogForum, 12(2), 147-156 (2016)

11. M.Ya. Postan, L. Filina-Dawidowicz, Model of Stochastic Optimization for Deteriorating Cargo Inventory Control at Port's Terminal. In: "Dynamics in Logistics" - Proceedings of the 2018 International Conference LDIC2018, Berlin: Springer: 41-52 (2018)

12. B.P. Dash, T. Singh, H. Pattnayak, An Inventory Model for Deteriorating Items with Exponential Declining Demand and Time-Varying Holding Cost. Amer. J. of Oper. Res., 4, 1-7 (2014)

13. R. Li, H. Lan, J.R. Mawhinney, A Review on Deteriorating Inventory. Eur. J. of Oper. Res., 3(1), 117-129 (2010)

14. N.H. Shah, Y.K. Shah, Literature Survey on Inventory Models for Deteriorating Items. Econ. Annals, 44, 221-237 (2000)

15. M.Ya. Postan, L. Filina-Dawidowicz, Dynamiczny Model Optymalizacyjny Procesu Planowania Zapasow I Dostaw Zrożnicowanych Asortymentowo Produktow Szybko Psujacych się. In: Semenov, I.N., Wiktorowska-Jasik, A. (eds.) Transport $w$ Regionie Pomorza Zachodniego, Szczecin, 13-20 (2013) (in Polish)

16. M.Ya. Postan, L. Filina-Dawidowicz, Dynamic Optimization Model for Planning of Supply, Production, and Transportation of Perishable Product, In: Suchanek M. (ed.) "Sustainable Transport Development, Innovation and Technology" - Proceedings of the 2016 TranSopot Conference, Berlin: Springer, 235-244 (2017)

17. M.Ya. Postan, Economic-Mathematical Models Of Multimodal Transport, Odessa, Astroprint (2006) (in Russian)

18. L. Kushnir, M. Postan, A method of determination of port terminal capacity under irregular cargo delivery and pickup. East.-Europ. J. of Enterp. Techn., 4(4/3), 30-37 (2016)

19. J. Wegierski, Metody Probabilistyczne w Projektowaniu Transportu Szynowego, Wydawnictwo Komunikacji i Łączności, Warszawa (1971)

20. J. Imakita, Techno-Economic Analysis of the Transport System, Saxon House, England (1978)

21. E.N. Voevudski, M.Ya. Postan, Stochastic models in projecting of ports and in control of their operations, Moscow, Transport (1987) (in Russian)

22. Yu. Kruk, M. Postan, Development and Analysis of Dynamic Optimization Model of Transport Flows Interaction at Port Terminal. East.-Europ. J. of Enterp. Techn., 1(3), 19-23 (2016)

23. B.V. Gnedenko, I.N. Kovalenko, Introduction to Queueing Theory. 3d Ed. Moscow, Kom Kniga (2005) (in Russian)

24. L. Kleinrock, Queueing Systems: Problems and Solutions, NY, J.Wiley\&Sons (1996)

25. N.U. Prabhu, Stochastic Storage Processes. Queues, Insurance Risk, Dams, and Data Communications, 2nd Ed., Springer, Berlin (1998)

26. M.Ya. Postan, Yu.V. Kurudzhi, Modeling the Influence of Transport Units Movements Irregularity on Storage Level of Cargo at Warehouse. Acta Systemica, 12(1), 31-36 (2012) 